\title{
Narrativas de professores formadores: práticas pedagógicas no ensino com a oralidade e a escrita na perspectiva dos multiletramentos
}

\author{
Neide Castilho de Araújo Teno ${ }^{1}$ \\ Edinéia Leite dos Santos Oliveira ${ }^{2}$ \\ Maristela Zeviani ${ }^{3}$
}

\begin{abstract}
RESUMO
Este estudo vincula-se ao projeto "Memórias de professores: diálogos sobre o Letramento e o ensino da Língua Portuguesa - etapa II" objetivando reflexão acerca do ensino da língua portuguesa nas escolas públicas. Analisa o ensino da oralidade e escrita enquanto prática docente na perspectiva do multiletramento. Objetiva compreender práticas pedagógicas dos professores em formação em Letras, por meio da análise de fragmentos de narrativas orais e escritas desses professores. Utilizouse metodologia da análise de conteúdo de Bardin (2013) para análise dos dados com recorte para relação ensino e prática pedagógica, prática de ensino de textos orais e escritos, oralidade e escrita. Utilizou-se os teóricos Bakhtin/Volochínov (1997; 2014), Tfouni (2010), Josso (2010), Marcuschi, (2001), entre outros. Como resultado, constatou-se que os professores dominam observações da oralidade e da escrita com gêneros multimodais na construção de sentido relaciondo-os aos usos sociais da linguagem e articulação entre experiências vivenciadas em sala de aula.
\end{abstract}

PALAVRAS-CHAVE: Narrativas de professores. Oralidade e Escrita.

Multiletramento.

\footnotetext{
${ }^{1}$ Doutora em Educação/Letras/Pesquisadora Senior. Universidade Estadual de Mato Grosso do Sul-UEMS/ Dourados /Campo Grande, Brasil. Orcid: https://orcid.org/0000-0001-5062-9155.E-mail: cteno@uol.com.br.

2 Mestre em Letras. Universidade Estadual de Mato Grosso do Sul-UEMS/Campo Grande, Brasil. Orcid: https://orcid.org/0000-0003-1973-4090. E-mail: edineia-leite@ hotmail.com.

3 Mestranda em Letras. Universidade Estadual de Mato Grosso do Sul-UEMS/Campo Grande, Brasil.. Orcid: https://orcid.org/0000-0002-4418-7378. E-mail: maristelazeviani@ hotmail.com.
} 
Narratives of teacher educators: pedagogical practices in teaching with orality and writing from the perspective of multiliteracies

\begin{abstract}
This study is linked to the project "Teachers' memories: dialogues on Literacy and the teaching of the Portuguese Language - stage II" aiming at a reflection on the teaching of the Portuguese language in public schools. Analyzes the teaching of orality and writing as a teaching practice from the perspective of multiliteracy. It aims to understand the pedagogical practices of teachers undergoing training in Letters, through the analysis of fragments of oral and written narratives of these teachers. Bardin's (2013) content analysis methodology was used for data analysis with a focus on the relationship between teaching and pedagogical practice, teaching practice of oral and written texts, orality and writing. We used the theorists Bakhtin/Volochinov (1997; 2014), Tfouni (2010), Josso (2010), Marcuschi, (2001), among others. As a result, it was found that teachers dominate observations of orality and writing with multimodal genres in the construction of meaning, relating them to the social uses of language and articulation between experiences lived in the classroom.
\end{abstract}

KEYWORDS: Teachers' narratives. Orality and Writing. Multiliteracies.

Narrativas de formadores de docentes: prácticas pedagógicas en la enseñanza con oralidad y escritura desde la perspectiva de las multiherramientas

\title{
RESUMEN
}

Este estudio está vinculado al proyecto "Memorias de los profesores: diálogos sobre la alfabetización y la enseñanza de la lengua portuguesa etapa II", cuyo objetivo es una reflexión sobre la enseñanza de la lengua portuguesa en las escuelas públicas. Analiza la enseñanza de la oralidad y la escritura como práctica docente desde la perspectiva de la multialfabetización. Tiene como objetivo comprender las prácticas pedagógicas de los docentes en formación en Letras, a través del análisis de fragmentos de narrativas orales y escritas de estos docentes. Para el análisis de datos se utilizó la metodología de análisis de contenido de Bardin (2013) con un enfoque en la relación entre la enseñanza y la práctica pedagógica, la práctica docente de textos orales y escritos, la 
oralidad y la escritura. Utilizamos a los teóricos Bakhtin / Volochinov (1997; 2014), Tfouni (2010), Josso (2010), Marcuschi, (2001), entre otros. Como resultado, se encontró que los docentes dominan las observaciones de la oralidad y la escritura con géneros multimodales en la construcción del significado, relacionándolas con los usos sociales del lenguaje y la articulación entre experiencias vividas en el aula.

PALABRAS CLAVE: Narrativas de los profesores. Oralidad y Escritura. Multiliteración.

$$
* * *
$$

\section{Introdução}

O Ensino de Língua Portuguesa, mormente os da oralidade e da escrita, tem sido tema de muitos estudos e exposto a diversas transformações em conformidade com as novas perspectivas do ensino da contemporaneidade, com isso o papel da linguagem ganha contornos mais complexos. Essa temática não representa um estudo novo que se conjectura, pelo contrário, trata-se de uma discussão presente na formação de professores e nos ambientes acadêmicos. Os professores, cada vez mais imersos nas multiplicidades de linguagem e nas transformações da sociedade, estão buscado outros modos de agir e interagir, particularmente, em relação ao ensino de língua portuguesa. Os diferentes segmentos da escola, por sua vez, também se empenham nas relações sociais e nas interações como aspectos importantes para o processo de aprendizagem da oralidade e da escrita.

Desenvolvemos um pesquisa a nível de mestrado que envolveu professores que frequentaram um curso, também de mestrado, de uma instituição pública, e desenvolvem atividades em diferentes escolas públicas do Município de Dourados /MS. A metodologia utilizada, análise de conteúdo Bardin (2013), constituiu em uma técnica que possibilitou sistematização das mensagens e permitiram inferências para compreender os conhecimentos emanados da produção e recepção (variáveis inferidas) 
das experiências relatadas. Utilizamos as fases indicadas por Bardin (préanálise, exploração do material e tratamento dos resultados e a inferência e a interpretação), e de posse das categorias, selecionamos três para analises: relação de ensino e pratica pedagógica, pratica ensino de textos orais e escrito, oralidade e escrita e outras dimensões.

O recorte dessas categorias subsidiou na compreensão das práticas pedagógicas com o ensino da oralidade e escrita dos professores em formação, do curso de Letras, a partir de suas narrativas, objetivo do estudo. Alguns dizeres são comuns nas falas desses professores de Língua Portuguesa em considerar maior importância para o texto escrito em detrimento do oral. Isto é visto como uma crença do bem escrever, de um lado a norma culta, como uma modalidade que só se aprende na escola, nos gêneros da literatura considerados como exemplos de um texto escrito. Por outro, encontra-se a oralidade, de cunho informal cujo aluno aprende em qualquer ambiente. $\mathrm{O}$ que sugere dizer que, no contraponto entre o formal/informal, culto/padrão, encontra-se o rigor da escrita como nível culto/padrão. Diante desse impasse, é importante indagar o papel da escola. A instituição de ensino tem dado conta de um ensino da oralidade e da escrita na perspectiva dos multiletramentos?

$\mathrm{O}$ avanço das tecnologias tem exigido dos professores um ensino que vai além do universo escolar dos sujeitos e ancora também na vida cotidiana. Isso implica no conhecimento dos multiletramentos, permitindo aos indivíduos o uso de competências mais elaboradas como os recursos linguísticos presentes nas diversas mídias digitais. Dentro deste contexto, o ensino exige outras práticas do professor, exige adequação, ressignificação das práticas pedagógicas. Podemos dizer de uma nova concepção de ensino em que os professores buscam reflexões nos letramentos múltiplos, que discorrem sobre competências e habilidades como requisitos necessários em situação de aprendizagem e podem proporcionar a formação de leitores críticos como uma transformação do ensino. É nesses estudos que nos baseamos para refletir sobre esse desafio da educação atual. 
O estudioso Bazerman (2007) defende a leitura, a oralidade e a escrita como uma articulação discursiva, provocada pelo hibridismo da linguagem (multiletramentos) além de fazerem, de certo modo, parte de práticas sociais dos sujeitos. Essas práticas socioculturais, no contexto das escolas, enquanto agências mediadoras das práticas letradas, são formas de garantir o desenvolvimento interacional e cognitivo dos sujeitos, proporcionando autonomia e ampliando a aprendizagem. Este estudo pretende, assim, aliar a outras pesquisas já realizadas informações diversas sobre o ensino da oralidade e da escrita, com o objetivo de compreender práticas pedagógicas com o ensino da oralidade e da escrita dos professores em formação, do curso de Letras, a partir de suas narrativas.

Recorremos às leituras de estudiosos como Bakhtin/Volochínov (1997; 2014), Tfouni (2010); Marcuschi, (2001), Rojo (2009), Rojo e Almeida (2012), entre outros para subsidiar a fundamentação e reflexões sobre a prática da oralidade e da escrita. A preocupação do estudo é compreender os multiletramentos como basilares no contexto atual de ensino e uma possibilidade para a interação com diferentes textos no ensino da oralidade e da escrita.

Para compreender os estudos das práticas de oralidade e escrita buscamos subsídios no multiletramento que vêm recebendo dos estudiosos da língua tratamento diferenciado no campo das ciências linguísticas e da linguagem. Tanto o letramento como o multiletramento estão vinculados ao conhecimento da leitura e da escrita e podem agrupar as práticas de uso da escrita nos diferentes contextos. Assim, como as relações sociais e comerciais foram mudando as famílias, as escolas, a sociedade acompanha essas mudanças ao longo da história, e com isso outras concepções surgem no ensino da língua, do que é ser letrado e do que é necessário para se apropriar do uso da escrita ao longo da vida (KLEIMAN, 2005).

Enquanto a oralidade busca nas práticas sociais a fala e a escrita para fins comunicativos sob vários gêneros textuais em variados contextos, o letramento envolve outras práticas da escrita na sociedade envolvendo desde 
o grafonêmico (unidades do alfabeto, como letras, til, sinais, pontuação), pois o mais letrado, a partir do momento que identifica a placa do ônibus, reconhece cálculos complexos, sabe distinguir as mercadorias pela marca, no entanto não lê revistas e jornais. Ë considerado letrado aquele que participa de maneira significativa de eventos de letramento e não aquele que faz apenas o uso formal da escrita (KLEIMAN, 2005).

O estudo da linguagem oral tem a preocupação com a situação de fala, o que a torna um objeto de análise. Dentro do seu contexto de uso, a linguagem oral envolve as práticas de uso na sociedade criando condições para estudos da linguística textual, pois é nesse momento: “[...] que se criam condições propícias para o surgimento de uma linguística do texto/discurso, ou seja, uma linguística que se ocupa das manifestações linguísticas produzidas pelos falantes de uma língua em situações concretas, sob determinadas condições de produção" (VILELA; KOCK, 2001, p. 412).

O ensino da oralidade na escola tem se restringido a identificação do erro $^{4}$ e se distanciado da concepção das variantes linguísticas, uma restrição que pode justificar o fracasso escolar de muitos alunos e pode estar relacionada à forma como os professores lidam com a oralidade e a escrita na escola. Os alunos trazem para a escola seu modo de falar próprio, com redução de fonemas, ditongações, abreviações, utilizando expressões do contexto informal e aceitas pela norma-padrão, embora não seja usual na linguagem formal.

\section{Algumas reflexões sobre oralidade e a escrita}

A relação oralidade e escrita teve seu momento de supremacia ao serem comparadas uma e outra. Prevalecia a ideia de que a concepção de oralidade estava concentrada em contextos informais, enquanto a escrita era de uso

\footnotetext{
${ }^{4}$ Com relação a considerar o erro nas questões do uso da oralidade (BORTONI-RICARDO, 2005; p. 14) salienta que a escola "norteada para ensinar a língua da cultura dominante; tudo o que se afasta desse código é defeituoso e deve ser eliminado", é essa posição da escola quando se trata do ensino da variedade culta da língua e das normas de sua gramática. Conforme Bortoni-Ricardo (2004, p. 62) "não existem fronteiras bem marcadas entre os eventos de oralidade e de letramento. As fronteiras são fluidas e há muitas sobreposições".
} 
exclusivamente para situações formais. Diante dessa ideia, a fala era vista como "mutável, heterogênea" e a escrita era considerada de um sistema mais "racional, estável, homogênea". Complementa Rojo e Schneuwly (2006), que

[...] a fala seria não-planejada e a escrita, planejada e permanente; a fala seria o espaço do erro e a escrita, o da regra e da norma, enquanto a escrita serviria para comunicar à distância no tempo e no espaço; a fala somente aconteceria face a face; a escrita se inscreveria, a fala seria fugaz; a fala é expressão unicamente sonora; a escrita, unicamente gráfica (ROJO; SCHNEUWLY, 2006, p. 464).

Essa tradição permeou, por alguns anos, não apenas a sociedade, mas também as escolas, que tinham a crença de que a oralidade constituía em algo não planejado e aceitável como uma maneira indiferente dos meios sociais. Os estudos de Kleimam (2005, 2003) e os de Street $(2004,2010)$, acerca do letramento, trouxeram uma nova visão para as práticas escolares, para os documentos oficiais e os livros didáticos. Os estudos desses estudiosos trouxeram ainda para a oralidade e letramento considerações significativas nas práticas sociais, e o valor que ocupa a oralidade e a escrita nas mais diversas situações, fazendo cair por terra o mito da supremacia da escrita, e ganhando força o ensino de oralidade como um modo de reconhecer o que os alunos sabem e o que é possível aprender.

A estudiosa Josso (2010) destaca a importância de analisar narrativas de professores, porque eles relatam, a partir de suas experiências, o modo como utilizam sua formação em sala de aula. Assim, as narrativas passam a constituir material de objeto de estudo com experiências significativas para trazer para a realidade aprendizagens e itinerários representativos que constituem saberes formativos.

Experiências de vida e de formação foram tema de reflexão e estudo das narrativas enquanto objeto de pesquisa como intercessão educativa. Nascidas de experiências de vida e formação, as narrativas já foram muito utilizadas nos diferentes contextos de formação para compreender as 
relações de formação dos sujeitos e repensar acerca da experiência vivenciada por estes sujeitos (JOSSO, 2010).

Sobre o conhecimento dos professores acerca do ensino, os estudiosos Souza e Abrahão (2006) encontram nas narrativas, estratégias de estudo, que revelam todo conhecimento da consciência, das aprendizagens, das crenças que o sujeito vivencia, além de colocar o sujeito como investigador da sua própria história. Desta forma, consideramos a abordagem das narrativas uma metodologia que possibilita estratégias para compreender as práticas pedagógicas e culturais do cotidiano dos sujeitos em formação.

Para compreender a importância do estudo, faz-se necessário refletir um pouco, sobre algumas questões relativas à oralidade e sua relação com a escrita a partir de narrativas de professores. Outros pesquisadores se posicionam acerca dessa relação e confirmam que a oralidade ocupava um lugar de superioridade sobre a escrita e isto se conservou, por muito tempo, no meio linguístico ocasionando muitos estudos a partir do momento em que os investigadores começaram a vêlas como práticas sociais diferentes. Essa posição é defendida por Marcuschi (2001), por exemplo, explicando que na contemporaneidade:

[...] predomina a posição de que se pode conceber oralidade e letramento como atividades interativas e complementares no contexto das práticas sociais e culturais. Uma vez adotada a posição de que lidamos com práticas de letramentos e oralidade, será fundamental considerar que as línguas se fundam em usos e não o contrário (MARCUSCHI, 2001, p. 17).

Essa disposição do estudioso depõe para a dinamicidade da linguagem e sua constante transformação, pelos sujeitos que a utilizam, e as apropriações que fazem por meio de um processo contínuo de uso. Ele busca em Street (2004, p. 2) a explicação para justificar a dimensão do termo letramentos e não letramento, uma vez que não tem como confundir as "diversas manifestações sociais do letramento com a escrita como tal, pois esta não passaria de uma das formas de letramento, ou seja o letramento 
pedagógico". Para novas visões do letramento, é importante situar leitura e a escrita em seus contextos sociais, posição reconhecida como fundamental para entender que não há apenas um letramento e sim letramentos.

Essa dimensão remete ao que postula Tfouni (2010, p. 21), acerca da afinidade entre a escrita e a oralidade, pois entende que trata de uma relação de não-dependência uma da outra, "mas é antes uma relação de interdependência, isto é, ambos os sistemas de representação se influenciam igualmente". Antes de mais nada, é necessário considerar que a oralidade e a escrita são atividades que se aprendem tanto na escola como na sociedade e de caráter comunicativo e de práticas situadas.

A posição dessa estudiosa é a de não manutenção da afinidade de oralidade e escrita, e filtrar dos textos escritos as questões de erros que remetem a fatos da fala, mesmo porque "não existe questão fechada acerca do que seja letramento" (TFOUNI, 2010, p. 31). No dizer da autora, o letramento abrange os "aspectos sócio-históricos da aquisição da escrita", e tem o fito de descrever o que ocorre no contexto social, mais do que isso, tem a finalidade de "investigar não somente quem é alfabetizado, mas também quem não é alfabetizado, e nesse sentido, desliga-se de verificar o individual e centraliza-se no social" (TFOUNI, 2010, p. 12). Ademais, podemos pensar que, pela perspectiva sócia histórica e discursiva, podese interrogar valores acerca da oralidade desprestigiando uma sobre a outra, ou seja, desvalorizar a oralidade diante da escrita.

Nessa seara, podemos olhar para a construção das narrativas dos professores em formação, quando ao narrar sobre questões de ensino e a oralidade constroem ditos de forma a conquistar seus interlocutores por meio dos efeitos de sentido garantindo autoria, "a sensação de cumplicidade entre narrador e leitor/ouvinte, ou ainda a criação de um efeito de suspense, seriam preenchidos pela função-autor" (TFOUNI, 2010, p. 55). Assim, é possível encontrar autoria nos discursos (denominados de narrativas) por meio dos efeitos de sentido. 
Igualmente, completa Marcuschi (2001) que, no modelo de sociedade que temos, a escrita, sendo uma exigência formal da sociedade, favorece o surgimento de muitos tipos de letramentos inclusive porque vai além da alfabetização e da informatização. $\mathrm{O}$ fato da oralidade ter se tornado tão necessária à sociedade, isso já lhe atribui caracteres que a torna com uma forte tendência para status de superioridade. Entretanto, de acordo com o estudioso, isso não torna a fala superior à escrita e tampouco admite a conviç̧ão de que a fala é primária.

Com relação à oralidade e escrita, Vilela e Koch (2001, p. 454) situam contribuições importantes ressaltando que os diversos tipos de textos produzidos em nossa sociedade são produções textuais que se situam em um "contínuo tipológico, em cujas extremidades estariam, de um lado, as escritas formais e, de outro, a conversação espontânea". Por isso, podem-se falar de textos mais conversacionais como (bilhetes, cartas familiares, textos de humor), como podem-se falar de textos falados mais próximos da escrita formal (conferências, entrevistas profissionais, ata administrativa), além daqueles textos ditos mistos ou intermediários presentes no meio social.

O construto elaborado mostra que a prática de ensino de textos orais e escritos não pode ser visto sob uma única teoria. Todo entendimento de fatos sociais, culturais manifestados na língua em textos orais e escritos deve ser considerado por várias correntes teóricas.

\section{Letramento e multiletramentos}

O conceito de letramento já está presente nos diferentes discursos da sociedade e da escola nos documentos oficiais da educação como os Parâmetros Curriculares Nacionais (PCNs), tanto que encontramos muitos estudos envolvendo essa temática. Trata de um conceito utilizado pelas diferentes áreas do conhecimento, a citar entre elas: a linguística aplicada, a educação, a didática, a história da leitura, envolvendo os usos da oralidade leitura e escrita. Por isso, o conceito de letramento, compõe o pano de fundo das atividades propostas nesta pesquisa. 
Os estudos de Kleiman (2003; 2005) sobre o letramento abordam considerações importantes sobre o que não é o letramento. O primeiro princípio alerta para a questão do letramento ser um método de ensino ou não. Posiciona-se que o letramento não é um método, mas é uma prática profissional, um conjunto de atividades que o professor apropria-se com vistas à compreensão da leitura e da escrita. Trata de uma outra maneira de ver o papel e o impacto da língua falada e escrita na sociedade, são as novas relações em diferentes espaços que o professor precisa estabelecer em seu cotidiano.

Essa denominação letramento traz como contrapartida novos olhares e saberes profissionais, onde é possível os usos da linguagem e seus modos de organizar a realidade, observando os diferentes contextos sociais, conforme Kleiman (2005). Esse viés abre espaço para uma nova forma de conceber a relação entre o escrito e o oral, como uma relação de continuidade e a ampliação do universo textual, o que indicia o professor a incluir em seu planejamento um ensino que vai além do livro didático, oportunizando aos alunos novos gêneros e novas práticas sociais.

Rojo e Almeida (2012, p. 8) vão de encontro a Cope e Kalantzis (2000) ao defenderem uma Pedagogia dos multiletramentos dada a diversidade de linguagens presentes na sociedade, e definem multiletramentos como sendo "o uso de novas tecnologias da comunicação e de informação ("novos letramentos') [...] de gêneros, mídias e linguagens [...]", de maneira que envolva o aluno com uma gama de textos/discursos variados, com a finalidade de ampliar o conhecimento cultural e aquisição de outros letramentos.

A prática de ensino de língua portuguesa que envolva as novas tecnologias pressupõe alunos e professores que tenham habilidades e competências de lidar com essas tecnologias. Rojo e Almeida (2012, p. 19), em seus estudos sobre multiletramentos, explicam sobre a importância da leitura de "textos compostos de muitas linguagens (ou modos, ou semioses) como uma nova prática de ensino" e exemplifica com textos multimodais ou multissemióticos, citando, vídeos, panfletos comerciais, publicitários, 
anúncios jornalísticos que circulam na sociedade e nos contextos digitais. Estas estudiosas questionam:

Por que abordar a diversidade de linguagens na escola? Há espaço para estudos multissemiose? Por que propor uma pedagogia dos multiletramentos? A partir dessa ótica de pensamento traçou-se o seguinte proposto: é possível uma prática de leitura de textos orais e escritos na escola? O que narram os professores sobre o ensino da prática de leitura de textos orais e escritos na perspectiva dos multiletramentos? (ROJO; ALMEIDA, 2012, p. 19).

Narrativas de profissionais envolvidos com o ensino traz reflexões pessoais, mas abordam também questões enunciativas de diferentes espaços por onde estiveram, por exemplo, a universidade. Os enunciados vão constituir marcas de escrita, que no dizer de Bakhtin (1997, p. 294) "serão marcas da voz de autoridade ou um enunciado investido de autoridade" que vai emergir na formação docente, adentrar na prática pedagógica desses professores com fim de legitimar seus fazeres.

O caminho de análise deste estudo adota como referência os estudos de Bardin (2013) que utiliza a análise de conteúdo para dar resposta aos questionamentos inicialmente elencados na pesquisa. Trata-se de uma metodologia de estudo que envolve procedimentos como: 1) pré-análise, 2) exploração do material e 3) tratamento dos resultados, inferência e interpretação. A primeira fase é aquela que se organiza o material a ser analisado sistematizando segundo o objetivo proposto. A segunda consiste no sistema de codificação e identificação das unidades de registro e unidades de significação, visando frequência dos registros e a descrição analítica. A terceira fase corresponde ao tratamento dos resultados, dando espaço para a inferência e interpretação. Nesta fase, o pesquisador pode condensar os dados e dar destaque para o que é pertinente ao estudo, momento da intuição, da análise reflexiva e crítica.

Do recorte realizado, para este estudo, limitou-se em analisar narrativas de duas professoras de língua portuguesa, formadas há mais de dez anos que desenvolvem suas atividades de docência em Escolas públicas 
do ensino básico. Buscamos nos saberes múltiplos, nas vozes das professoras explicações sobre o processo reconstrutivo da leitura, de sua prática tanto na oralidade como na escrita. Os sujeitos nomeados são fictícios com o intuito de preservar a privacidade dos sujeitos. Restringiuse em analisar categorias que envolvessem a prática de leitura com textos multimodais e sua relação com a oralidade e escrita. Assim, elegemos três categorias a saber: relação de ensino e prática pedagógica, prática ensino de textos orais e escritos, oralidade e escrita e outras dimensões.

\section{Relação ensino e prática pedagógica}

As narrativas sobre a relação de ensino e prática pedagógica desenvolvida ao longo da docência, os professores relatam diferentes crenças e atribuíram o insucesso de suas práticas de ensino na organização e na precariedade da escola. Assim narram:

Luciana: Não tem como exigir um ensino de qualidade quando na escola não temos o básico. Falta espaço para montar a biblioteca, falta merenda, falta boa vontade dos governantes. Minha carga horária é distribuída em duas escolas, com realidades bem diferentes, enquanto uma os alunos frequentam biblioteca, manuseiam livros, frequentam a quadra, [...] a outra as condições são péssimas, na verdade o professor tem que adaptar tudo e conforme a realidade. Eu até tenho ideias de trazer um ensino diferente para os alunos, mas a escola não ajuda. Nunca tem dinheiro para nada, a coordenação não oferece um sulfite, uma fotocopia, um livro diferente. Agora chegou a internet. Eu até tenho ideias de trazer um ensino diferente para os alunos mas não da. E se pensar o aluno fica com nos professores todo ensino fundamental e conhece bem a escola.

Pedro: Minha formação considero que foi boa, aprendi como lidar com os alunos, como organizar um planejamento. $\mathrm{O}$ que eu acho difícil é a escola, que não proporciona nada, tem dia que nem o ventilador. Não temos sala de informática, não temos computadores para os alunos, e a biblioteca está num espaço adaptado. Nós professores não temos apoio para desenvolver uma aula 
boa. Eu sei como fazer, mas falta estimulo. Nos professores convivemos muito com os alunos por longo tempo e as vezes até todo ensino fundamental e podemos perceber o crescimento do aluno durante esse tempo.

As narrativas dos professores fazem uma denúncia da estrutura da escola e dos moldes de uma sociedade "sucateada" na educação. A prática de ensino do professor limita-se "nada pode, nada tem". Nesse entorno, descrevem a impossibilidade de um ensino diferente dada as condições que encontra as escolas. Uma prática de ensino como um estranhamento de atividades inovadoras, "sabe fazer mas falta estímulo". Ressalta a autonomia e o conhecimento como um meio de prática que as tornam cerceadas de caminhar para uma prática nova, conforme depõe Novoa (1992, p. 23) que "[...] a inovação pertence ao próprio professor que se encontra no cerne da atividade educativa." Há um reconhecimento que existe uma prática nova "Eu até tenho ideias de trazer um ensino diferente para os alunos", há um reconhecimento da necessidade de aprendizagem conforme explica Novoa (1992) que as mesmas fortalecem o exercício docente no lócus da sala de aula, mas também é, neste espaço, que a prática de ensino é avaliado pela professora como improbabilidade e inquietações.

Trazem as narrativas de Luciana e Pedro excertos que depõem para o tempo que o aluno fica sob a responsabilidade dos professores:

Luciana: aluno fica com nos professores todo ensino fundamental e conhece bem a escola.

Pedro: professores convivemos muito com os alunos por longo tempo e as vezes até todo ensino fundamental e podemos perceber o crescimento do aluno durante esse tempo.

Diante dessas situações expostas pelos professores acima, pressupõese que estes assumam também o papel de pesquisadores, já que observam e estudam o que cada aluno faz com a oralidade e a escrita dentro do contexto em que esses usos ocorrem. Sem nos esquecer, que esses professores atribuem o insucesso de suas práticas de ensino a uma situação de desorganização e precariedade das escolas. 


\section{Prática de ensino textos orais e escritos}

Ao narrar sobre prática de ensino de textos orais e escritos os professores relatam sobre as atividades que realizam com os textos orais e escritos na sala de aula, e muitas categorias vieram nos depoimentos. As narrativas falam de leituras jogralizadas, cantadas, em grupo, teatralizadas, como uma maneira diferente de pratica de ensino. Assim narram:

Luciana: Eu levo para sala de aula com muitos textos com diferentes gêneros. Eu acho difícil separar oralidade da escrita, eu acho que uma está ligada a outra, muito complicado ensinar a escrita sem a oralidade. Uma atividade que sempre faço é pedir que relatem um acontecimento que eles viram, peço para eles defenderem uma ideia, uma posição deles sobre um ponto de vista. Peço para fazer uma pergunta para o outro. Isso tudo eu faço como pratica de ensino com a oralidade. Levo poemas, músicas, trava língua. $\mathrm{Na}$ oralidade é que tenho oportunidade de mostrar a norma culta e popular ao aluno, a gente não escreve como se fala. Utilizo bastante textos orais na sala de aula porque sei que os alunos aprendem a falar e viver bem fora da escola.

Pedro: Sempre início pelo trabalho com a oralidade, os alunos apreciam muito os textos orais, principalmente se o gênero tiver imagem complementando o texto, quanto mais colorido, mais eles gostam. Leitura coletiva, leitura oral, jogral, é uma das minhas práticas com oralidade, os alunos trazem textos de propagandas e fazemos leituras de diferentes modos. Na leitura e interpretação dos textos os alunos falam de toda composição que há nos textos, fala da cor, da imagem, reconhecem desenhos.

Os excertos das narrativas depõem para uma prática pedagógica de um estudo que não abandona a importância e a necessidade de se ensinar a norma padrão na escola, "na oralidade é que tenho oportunidade de mostrar a norma culta e popular ao aluno" (BORTONI-RICARDO, 2004, p. 74), mas é preciso observar a fala do aluno, pois chegam à escola já sabendo compor sentenças bem formadas e comunicar-se nas diversas situações. Mas ainda não tem uma gama muito ampla de recursos 
comunicativos que lhes permitam realizar tarefas comunicativas complexas em que se exija muita monitoração. É papel da escola, portanto, facilitar a ampliação da competência dos alunos, permitindolhes "apropriarem-se dos recursos comunicativos necessários para se desempenharem bem, e com segurança, nas mais distintas tarefas linguísticas" (BORTONI-RICARDO, 2004, p. 74).

Para Marcuschi (2001, p. 25), o narrar que "utiliza textos orais na sala de aula porque sabe que os alunos aprendem a falar e viver bem fora da escola”, depõe para uma prática de ensino sob o viés do letramento, pois há um reconhecimento do aprender para a vida, com um valor social, entretanto há uma consideração destacada para a importância do ensino com a oralidade nos diferentes contextos sociais. $\mathrm{O}$ entendimento de que a oralidade é aprendida nas relações sociais trata de uma prática diferente, de situação comunicativa, uma vez que o contexto tem forte influência no tipo de linguagem que se deve usar. Assim, a prática da oralidade é uma forma de inserção cultural e de socialização, que, ainda segundo Marcuschi (2001, p. 25) "[...] trata de uma prática social interativa para fins comunicativos que se apresenta sob várias formas ou gêneros textuais[..] mais informal à mais formal nos mais variados contextos de uso".

Quando o depoente narra apontando os diferentes gêneros na sua prática de ensino e que inicia pela oralidade para chegar a escrita, há o reconhecimento da importância da continuidade do ensino com gêneros orais e escritos. Inferimos nessa narrativa a mútua interdependência, dos gêneros orais, quando adentram para o contexto da sala de aula, para atingir a produção textual, um ensino que pressupõe o oral, por isso "há sempre o falar para escrever, o escrever para falar, o escrever para escrever e o falar para falar" (SCHNEUWLY, 2005, s. p.), mostrando a interdependência de um gênero e outro, assim como de outros gêneros, o que contribui para conhecer a intertextualidade entre os textos. 


\section{Oralidade e escrita e outras dimensões}

Essa categoria destacada nas análises envolve a prática pedagógica em outras dimensões como sala de informática, livro didático, jornais, revistas. Outras dimensões foram estendidas também como outros modos de ler.

Luciana: Uma atividade em sala de aula, que realizei com os alunos no celular foi a busca em sites de propagandas do dia das mães, poemas, imagens. Os alunos tanto liam, como davam opiniões sobre a imagem que estavam olhando. Foi um momento que estava presente a oralidade e troca de leituras. Alguns alunos relacionavam a imagem do site com os objetos do mercado. $\mathrm{Na}$ produção de cartões os alunos tiveram momentos de rescrita para melhorar a linguagem utilizada e estar mais próximo da norma culta. Toda produção foi acompanhada de ilustrações, desenhos, ícones.

Pedro: Recorri aos gêneros textuais do livro didático para trabalhar os elementos da organização do texto oral, as pausas, as entonações, no truncamento na fala, nas hesitações nas repetições. Para o domínio da oralidade, acredito em práticas pedagógicas voltadas para situações que incentivem os alunos a falar, expor e debater sobre variados temas sociais. Expor aos alunos diferentes gêneros como: panfletos, propagandas, entrevistas, histórias em quadrinhos, é uma maneira de mostrar a diferença do oral e do escrito. Sei que todo professor deve estar atento para atividades com a língua oral em sala de aula, que mostre ao aluno não só a importância de usar a norma padrão, mas aprender a necessidade desse uso em diversos contextos sociais.

O excerto de Pedro dá destaque para vocábulos como "entonações, truncamentos, repetições, hesitações" que de certa maneira constrói sua prática com materialização de atividades pedagógicas calcadas em elementos organizacionais da conversação: turnos, tópicos, situação, modo do discurso. Marcuschi (2001) explicita essa metodologia como sendo a valorização da presença dos marcadores textuais enfatizando a importância para as pausas e o tom de voz e desconsiderando os demais marcadores linguísticos que são o olhar, a gesticulação, os movimentos corporais como fundamental na interação e compreensão da leitura. Entretanto, o excerto destaca os fatores pragmáticos 
expressos nas "pausas, entonações, no truncamento na fala, nas hesitações nas repetições" exercendo função relevante na fala e na escrita. De certa maneira, há uma confusão teórica entre texto oral e escrito, o que infere uma prioridade ao texto escrito à medida que expõe que "essas atividades orais considero importante porque na escrita facilita ao aluno e ele percebe a diferença do oral e escrita".

As narrativas de Pedro e Luciana trazem em seu bojo a preocupação de um ensino com a oralidade e escrita, à medida que propõem atividades com diferentes gêneros textuais, certos de que nessa ótica estão propiciando conhecimento do uso da linguagem oral e escrita, já que os PCNs (BRASIL, 1998) orientam a escola para um ensino com a linguagem oral, norteando o professor a inserir no planejamento a utilização de diferentes gêneros textuais como: apresentações públicas: realizações de entrevistas, debates, seminários, apresentações teatrais, como uma maneira de propor situações didáticas que estimule o aluno a utilizar tanto o nível oral como o nível escrito, em diferentes situações. "A aprendizagem de procedimentos apropriados de fala e de escuta, em contextos públicos, dificilmente ocorrerá se a escola não tomar para si a tarefa de provê-la" (BRASIL, 1998, p. 26).

O fato de os alunos lançarem-se em produções textuais arriscando diferentes recursos (cores, ícones, formas, tamanho de letras), estão testemunhando a presença de práticas multimodais. O livro didático tem propiciado um infinito de gêneros textuais com elementos imagéticos e visuais, contribuindo para efeito de sentidos na composição textual.

Costa Val (2004), ensina que, com a semiótica, houve modificações na conceituação de texto, ampliando a definição de texto "como qualquer produção linguística, falada ou escrita, de qualquer tamanho, que possa fazer sentido numa situação de comunicação humana, isto é, numa situação de interlocução" (grifo nosso). Dentro dessa perspectiva, podemos entender o texto como uma prática linguística, (oral ou escrita), fazendo parte da comunicação e efetivada também na oralidade.

Os excertos de Luciana e Pedro traz à tona um ensino com a oralidade e a escrita mas acrescenta a importância de olhar para outros modos de 
representação, o que pode ser definido com multimodalidade. Dionísio (2007, p. 178) compreende o multimodal tanto para os textos escritos como os orais, e destaca outros como a linguagem oral e gestual, pois "palavras e gestos, palavras e entonações, palavras e imagens, palavras e tipografia, palavras e sorrisos, palavras e animações etc.” são caraterísticas da multimodalidade.

Alguns gêneros como noticiários de TV, novelas, peças teatrais situam na interface entre a fala e a escrita são organizados para serem de uso oral, porém são também transmitidos pela escrita. São gêneros midiáticos, fruto dos avanços tecnológicos e nesse contexto encontramos os chamados gêneros híbridos, com o fito de inovar, transformar e mesclar tanto na sua forma como no seu conteúdo. Dada sua especificidade de serem orais antes da serem escritos são textos que de certa forma constroem efeitos diferentes dentro de um processo de aprendizagem (PINHEIRO, 2002).

Segundo os estudos de Kleimam (2005, 2003) e os de Street (2004, 2010), acerca do letramento, a questão do ensino da oralidade e escrita envolvem as práticas sociais e tem a interatividade como uma atributo de qualquer uso da língua. Por isso, tanto o oral como o escrito encontramos marcas interativas. Marcuschi (2001) defende a hipótese de que a oralidade e a escrita se dão dentro de um continuum tipológico das práticas sociais, o que implica dizer que a oralidade e a escrita não situam se em polos opostos, porém são consideradas como modos complementares de enunciação.

As narrativas dos professores em formação, neste estudo, trazem uma amostra de um ensino de construção de conhecimento, que podem ser olhadas sob duas óticas: uma está no fato desses sujeitos narrarem suas práticas por meio de uma relação dialógica entre sujeitos e discursos; e a outra de olhar como o sujeito compreende e singulariza suas narrativas. Os recortes depõem para uma aproximação de práticas de oralidade e escrita no contexto escolar, permitindo situar estas práticas no contexto sócio-histórico (incentivem os alunos a falar, expor e debater sobre variados temas sociais). Esse modo de falar de sua experiência (LARROSA, 2004, p. 129) compreende como sentido 
das coisas, um "saber experiência tem algumas características essenciais que o opõem, ponto por ponto, ao que entendemos como conhecimento".

\section{Considerações finais}

As narrativas de experiências da prática pedagógica dos professores em formação apontaram para a construção das percepções das relações de suas práticas no contexto da sala de aula, como mostraram possibilidades de aprendizagens com os gêneros textuais. Nos fragmentos analisados, há uma articulação entre o ensino e a crença da aprendizagem da oralidade e da escrita a partir das experiências vivenciadas, assim como as narrativas se apresentaram como um espaço privilegiado para repensar as práticas pedagógicas e ressignificação alguns aspectos da formação quanto aos conteúdos que devem ser priorizados no ensino.

Os fragmentos das narrativas evidenciaram uma atuação do professor com o domínio das observações da oralidade e da escrita com gêneros multimodais apresentando destaques para o conjunto de caraterísticas que constroem sentido, a multimodalidade que vão além da oralidade e da escrita, ou seja, a diversidade das linguagens que constituem os textos. O ensino da oralidade e da escrita ganha extensão à medida que o ensino vincula-se à observação dos elementos semióticos, assim o sujeito se respalda para compreender as intenções, não só signos alfabéticos, como nos elementos imagéticos e visuais presentes nos textos.

\section{Referências}

BAKHTIN, M. Estética da criação verbal. São Paulo: Martins Fontes,1997.

BAKHTIN, M. (V. N. Volochínov). Marxismo e Filosofia da Linguagem. Trad. Michel Lahud e Yara Frateschi Vieira. 16 a ed. São Paulo: Hucitec, 2014.

BARDIN, L. Análise de Conteúdo. Lisboa, Portugal; Edições 70, 2013.

BAZERMAN, C. Escrita, Gênero e Interação Social. São Paulo Cortez Editora, 2007. 
BORTONI-RICARDO, S. M. Educação em língua materna: a sociolinguística na sala de aula. São Paulo: Parábola. 2004.

BORTONI-RICARDO, S. M. Nós chegemu na escola, e agora?: Sociolinguística e educação. São Paulo: Parábola Editora, 2005.

BRASIL. Parâmetros Curriculares Nacionais (PCNs). Introdução. Ensino Fundamental. Brasília: MEC/SEF, 1998.

COPE, B; KALANTZIS, M. (Eds.) Multiliteracies: Literacy Learning and the Design of Social Futures. Routlege: London, 2000.

COSTA VAL, M. G. Texto, textualidade e textualização. In: CECCANTINI, J. L. T.; PEREIRA, R. F.; ZANCHETTA JR., J. Pedagogia Cidadã: cadernos de formação: Língua Portuguesa. v. 1. São Paulo: UNESP, Pró-Reitoria de Graduação, 2004. p. p. 113-128.

DIONÍSIO, A. P. Multimodalidade discursiva na atividade oral e escrita (atividades). In: MARCUSCHI, L. A.; DIONÍSIO, A. P. (orgs.). Fala e Escrita. Belo Horizonte: Autêntica, 2007.

JOSSO, M.-C. Experiência de vida e formação. Natal: EDUFRN; São Paulo: Paulus, 2010.

KLEIMAN, Â. Preciso ensinar o letramento? Não basta ensinar a ler e a escrever? São Paulo: Produção Editorial, 2005.

KLEIMAN, Â. (org.) Os significados do letramento. Novas perspectivas sobre a prática social da escrita. Campinas, S. P.: Mercado de Letras, 6a. ed. 2003.

LARROSA, J. B. Notas sobre a experiência e o saber da experiência. In: Geraldi, C.M.C; RIOLFI, C. R.; GARCIA, M. de F. (orgs. ) Escola Viva. Campinas, S.P.: Mercado de Letras, 2004, p. 113-13.

MARCUSCHI, L. A. Letramento e oralidade no contexto das práticas sociais e eventos comunicativos in: SIGNORINI, I. (org.) Investigando a relação oral/escrito e as teorias do letramento. Campinas - SP: Mercado de Letras 2001.

NOVOA, A. Os professores e a sua formação. Lisboa, PT: Dom Quixote, 1992.

NOVOA, A. Os professores e as Histórias da sua vida. In: NÓVOA António (org.) Vidas de professores. Portugal: Porto Editora, 1992.

PINHEIRO, N. F. A noção de gênero para análise de textos midiáticos. In: MEURER, J. L.; MOTTA-ROTH, D. (org.). Gêneros textuais e práticas discursivas: subsídios para o ensino da linguagem. Bauru, SP: EDUSC, 2002. p. 259-290. (Coleção Signum).

ROJO. Letramentos múltiplos, escola e inclusão social. São Paulo: Parábola Editorial, 2009. 128 p. 
ROJO; ALMEIDA, E. M. (Orgs.). Multiletramentos na escola. São Paulo: Parábola Editorial, 2012, 264 p.

ROJO; ALMEIDA, E. M.; SCHNEUWLY, B. As relações oral/escrita nos gêneros orais formais e públicos: o caso da conferência acadêmica. Revista Linguagem em (Dis)curso - LemD, Tubarão, v. 6, n. 3, p. 463-493, set./dez. 2006.

SCHNEUWLY, B. Gêneros orais e escritos na escola. Conferência proferida no Instituto de Estudos da Linguagem, da UNICAMP, em 20 out. 2005. Campinas: IEL/UNICAMP, 2005.

SOUZA, E. C.; ABRAHÃO, M. H. M. B. (Org.). Tempos, narrativas e ficções: a invenção de si. Porto Alegre: EDIPUCRS, 2006.

STREET, B. Letramento e alfabetização: as muitas facetas. Revista Brasileira de Educação, n. 25, Abril 2004, p. 5-17.

STREET, B. Os novos estudos sobre o letramento: histórico e perspectivas. In: MARINHO, M.; CARVALHO, G. T. Cultura escrita e letramento. Belo Horizonte: Editora da UFMG, 2010. p.33-53.

TFOUNI, L. V. Letramento e alfabetização. 9a. Ed. São Paulo/SP: Cortez, 2010.

VILELA, M.; KOCK, I. V. Gramática da língua portuguesa. Almedina Portugal, março 2001. 